\title{
Grazing of the dinoflagellate Noctiluca scintillans on the paralytic toxin-producing dinoflagellate Gymnodinium catenatum: Does grazing eliminate cells during a bloom?
}

\section{Pastoreo del dinoflagelado Noctiluca scintillans sobre el dinoflagelado productor de toxinas paralizantes Gymnodinium catenatum: ¿Elimina el pastoreo células durante un florecimiento?}

\author{
José J Bustillos-Guzmán ${ }^{1 *}$, Christine J Band-Schmidt², David J López-Cortés ${ }^{1}$, Francisco E \\ Hernández-Sandoval ${ }^{1}$, Erick Núñez-Vázquez ${ }^{1}$, Ismael Gárate-Lizárraga ${ }^{2}$ \\ ${ }^{1}$ Centro de Investigaciones Biológicas del Noroeste (CIBNOR), Instituto Politécnico Nacional 195, Col. Playa \\ Palo de Santa Rita Sur, La Paz, Baja California Sur, 23096, México. \\ ${ }^{2}$ Centro Interdisciplinario de Ciencias Marinas-Instituto Politécnico Nacional (CICIMAR), Departamento de \\ Plancton y Ecología Marina, Av. Instituto Politécnico Nacional s/n, La Paz, Baja California Sur, 23096, \\ México. \\ * Corresponding author. E-mail: jose04@cibnor.mx
}

\begin{abstract}
Temperature and nutrient concentrations were measured during a mixed bloom of Noctiluca scintillans and Gymnodinium catenatum in La Paz Bay, Gulf of California. Under laboratory conditions, we offered three concentrations of G. catenatum (312, 625, or 1015 cells $\mathrm{mL}^{-1}$ ) to $0.53 \mathrm{~N}$. scintillans cells $\mathrm{mL}^{-1}$ to study predation rates. Experiments were carried out with $750 \mathrm{~mL}$ of culture during a fiveday period. Sea surface temperature clearly showed a transitional period from colder to warmer water during the bloom. Field and laboratory data showed that $N$. scintillans fed on G. catenatum. During the trial, more than $70 \%$ of $N$. scintillans cells contained G. catenatum cells in their vacuoles. Ingestion rates varied; the highest ranged from 30 to $40 \mathrm{G}$. catenatum cells $\mathrm{h}^{-1}$ in each $N$. scintillans cell. A clear relation to the concentration of the diet was not evident. Low values of 1 to $3 \mathrm{G}$. catenatum cells $\mathrm{h}^{-1}$ in each $N$. scintillans cell were typical at the end of the trial. Noctiluca scintillans doubled in concentration about every $48 \mathrm{~h}$; however, numerous trophonts were observed leaving the cytoplasmic membrane, suggesting cell damage. These data indicate that $N$. scintillans ingests $G$. catenatum cells but the prey appears to damage predator cells in a relatively short time.
\end{abstract}

Key words: Gymnodinium catenatum, Noctiluca scintillans, grazing, biocontrol, La Paz Bay.

RESUMEN. Se monitoreó la temperatura y los nutrientes durante una proliferación de Noctiluca scintillans y Gymnodinium catenatum en la bahía de La Paz, golfo de California. También, bajo condiciones de laboratorio, se mezclaron diferentes concentraciones de G. catenatum (312, 625, o 1015 células $\mathrm{mL}^{-1}$ ) con 0.53 células de $N$. scintillans $\mathrm{mL}^{-1}$ a fin de evaluar las tasas de pastoreo. La experimentación se llevó a cabo en $750 \mathrm{~mL}$ de cultivo durante un periodo de cinco días. La temperatura superficial mostró claramente un periodo de transición de agua fría a caliente durante la proliferación. Las observaciones de campo y las de laboratorio mostraron que N. scintillans se alimentaba de G. catenatum. En el laboratorio, más del $70 \%$ de $N$. scintillans contenía células de G. catenatum en sus vacuolas. La tasas de ingestión variaron ampliamente; los valores más altos variaron de 30 a 40 células de G. catenatum $\mathrm{h}^{-1}$ en cada célula de $N$. scintillans. No se observó una relación entre las diferentes concentraciones de G. catenatum ofrecidas y la tasa de ingestión. Al final del experimento se observaron tasas de ingestión bajas de 1 a 3 células de G. catenatum $\mathrm{h}^{-1}$ en cada célula de $N$. scintillans. La concentración de $N$. scintillans se duplicó aproximadamente cada 48 h; sin embargo, observamos numerosos trofontes saliendo de su cubierta externa, lo cual sugiere que existió daño celular. Estos datos indican que $N$. scintillans ingiere a G. catenatum pero la presa parece dañar al depredador en un corto plazo.

Palabras clave: Gymnodinium catenatum, Noctiluca scintillans, pastoreo, biocontrol, bahía de La Paz.

\section{INTRODUCTION}

Noctiluca scintillans (Macartney) Kofoid and Swezy 1921 is a large heterotrophic dinoflagellate that forms conspicuous red tides around the world (Elbrächter and Qi 1998). It has a complex life cycle with at least 12 stages, where both the mature trophont and minuscule trophont with a completed tentacle have phagotrophic capacity

\section{INTRODUCCIÓN}

Noctiluca scintillans (Macartney) Kofoid y Swezy 1921 es un dinoflagelado heterótrofo grande que forma florecimientos algales evidentes en todo el mundo (Elbrächter y Qi 1998). Tiene un ciclo de vida complejo con al menos 12 estadios, en los cuales tanto los trofontes maduros como los pequeños que han desarrollado completamente el tentáculo 
(Fukuda and Endoh 2006). Its role as a predator of diatoms, dinoflagellates, and mesozooplankton has been described (Quevedo et al. 1999, Fonda-Umani et al. 2004, Escalera et al. 2007), as has its role as a vector of toxigenic algae (Escalera et al. 2007). In the Gulf of California, N. scintillans is an ubiquitous component of plankton and one of the main red-tide-forming species (Gárate-Lizárraga 1991, CortésAltamirano et al. 1995, Cortés-Altamirano and AlonsoRodríguez 1997). The vacuoles of this species contain toxigenic microalgae and may play an important role in the population dynamics of harmful algae (Alonso-Rodríguez et al. 2005, Escalera et al. 2007, Azanza et al. 2009). Excretion or bioconversion of ingested saxitoxin and analogues by N. scintillans to less potent analogues (Azanza et al. 2009, Frangópulos et al. 2011) provides additional support for this suggestion. The dinoflagellate Gymnodinium catenatum Graham 1943 is one of the main producers of paralytic shellfish poisons (PSP) and bloom-forming species off the west coast of Mexico. It is responsible for animal and human poisoning (reviewed by Band-Schmidt et al. 2010). To our knowledge, predator-prey interaction of these two species under natural conditions has only been described by AlonsoRodríguez et al. (2005), who described that the vacuoles of $N$. scintillans contained G. catenatum in a bloom along the coast of Sinaloa. They concluded that $N$. scintillans plays a role in bloom dynamics of $G$. catenatum and suggested that $N$. scintillans can be used as a biocontrol agent for this PSPproducing dinoflagellate.

From March through April 2007, as part of a monitoring program, G. catenatum and $N$. scintillans were found in La Paz Bay in the Gulf of California. During this bloom, a large percentage of $N$. scintillans cells contained G. catenatum cells in their vacuoles. The combination of these two microalgae in the bay gave us the opportunity to study the predatory capacity of $N$. scintillans on G. catenatum in the field and under laboratory conditions.

The purpose of this study was to confirm the grazing activity of $N$. scintillans on the smaller dinoflagellate $G$. catenatum, focusing on the proportion of $N$. scintillans cells containing G. catenatum and the grazing rates under laboratory conditions. Additionally, the physical and chemical conditions for the bloom are described to understand the possible causes for the presence of both species in La Paz Bay.

\section{MATERIALS AND METHODS}

\section{Field measurements}

As part of our monitoring program, samples were collected at five stations (fig. 1) located in the area of the $N$. scintillans bloom and immediate surroundings. Seawater surface temperature was measured with a bucket thermometer, and nutrient analyses (nitrate, phosphate, and ammonium) were done using a continuous flux ion autoanalyzer (QuikChem 8000 Series, Lachat Instruments, Milwaukee, tienen capacidad fagotrófica (Fukuda y Endoh 2006). Su papel como depredador sobre diatomeas, dinoflagelados y mesozooplancton ya ha sido documentado (Quevedo et al. 1999, Fonda-Umani et al. 2004, Escalera et al. 2007), así como su papel como vector de toxinas (Escalera et al. 2007). En el golfo de California, N. scintillans es una especie importante del plancton y una de las principales formadoras de florecimientos algales (Gárate-Lizárraga 1991, CortésAltamirano et al. 1995, Cortés-Altamirano y AlonsoRodríguez 1997). Como depredador, sus vacuolas alimenticias pueden contener algas tóxicas y jugar un papel importante en la dinámica de los florecimientos algales nocivos (Alonso-Rodríguez et al. 2005, Escalera et al. 2007, Azanza et al. 2009). Los procesos de bioconversión o excreción de la saxitoxina a sus análogos de menor potencia proveen información adicional para esta sugerencia (Azanza et al. 2009, Frangópulos et al. 2011). El dinoflagelado Gymnodinium catenatum Graham 1943 es uno de los principales productores de toxina paralizante de moluscos y formadores de florecimientos de la costa oeste de México. Esta especie ha sido responsable del envenenamiento de animales y humanos (revisado por Band-Schmidt et al. 2010). Hasta donde se conoce, la interacción de estas dos especies como depredador y presa en condiciones naturales sólo ha sido observada por Alonso-Rodríguez et al. (2005), quienes describieron que en las vacuolas de $N$. scintillans había $G$. catenatum durante un florecimiento en las costas de Sinaloa. Estos autores concluyeron que $N$. scintillans juega un papel importante en la dinámica del florecimiento de G. catenatum y sugirieron que $N$. scintillans podría ser usado como un agente de biocontrol de G. catenatum.

De marzo a abril de 2007, dentro de nuestro plan de monitoreo, encontramos a G. catenatum y $N$. scintillans en la bahía de La Paz en el golfo de California. Durante este florecimiento, se observó que un porcentaje importante de $N$. scintillans contenía células de G. catenatum en sus vacuolas. La coexistencia de ambas especies en la bahía nos dió la oportunidad de determinar la capacidad depredadora de $N$. scintillans sobre G. catenatum en condiciones de laboratorio y en el campo.

El propósito de este trabajo fue confirmar la capacidad depredadora de $N$. scintillans sobre G. catenatum, enfocándonos en determinar la proporción de $N$. scintillans que contenía células de G. catenatum y las tasas de depredación en condiciones de laboratorio. De forma paralela, se midieron las condiciones físicas y químicas en el ambiente para entender las condiciones ambientales que favorecieron la presencia de ambas especies en la bahía de La Paz.

\section{MATERIALES Y MÉTODOS}

\section{Mediciones en el campo}

Como parte del programa de monitoreo, se tomaron muestras en cinco estaciones (fig. 1) localizadas dentro del 
WI) and spectrophotometric methods, as described by Strickland and Parsons (1972).

\section{Isolation and culturing of Gymnodinium catenatum}

Vegetative cells of $G$. catenatum were collected from Concepción Bay in the Gulf of California with vertical tows of a 20- $\mu$ m phytoplankton net. The cell samples were sieved through a $60-\mu \mathrm{m}$ mesh to eliminate larger organisms. This concentrate was placed in $250-\mathrm{mL}$ culture containers containing seawater enriched with $\mathrm{f} / 2$ medium modified by adding $\mathrm{H}_{2} \mathrm{SeO}_{3}\left(0.01 \mu \mathrm{M} \mathrm{L}^{-1}\right)$ and $\mathrm{CuSO}_{4}$ concentration reduced to $0.01 \mu \mathrm{M} \mathrm{L}^{-1}$ (Anderson et al. 1984). In the laboratory, vegetative cells of $G$. catenatum were isolated from the enriched cultures with micropipettes under an inverted microscope (Axio Vert 100, Carl Zeiss, Oberkochen, Germany). Single cells and chains were transferred to 96 -well plates containing modified $\mathrm{f} / 2$ medium and maintained at $20 \pm 1{ }^{\circ} \mathrm{C}$ with an overhead illumination of $150 \mu \mathrm{mol}$ photons $\mathrm{m}^{-2} \mathrm{~s}^{-1}$ from cool white fluorescent lights in a 12:12 light:dark cycle. The clonal strain GCCV-7 of G. catenatum was used in our experiments. Details of the isolated strain can be found in the archives of the Live Dinoflagellate Collection (CODIMAR) at CIBNOR, La Paz, Mexico (Morquecho 2008). To provide sufficient cells for grazing experiments, strain GCCV-7 was grown in seven 1-L glass flasks in modified $\mathrm{f} / 2$ medium (Band-Schmidt et al. 2005) at $24-26 \pm 1{ }^{\circ} \mathrm{C}$ with seawater obtained from the inner bay of La Paz (salinity: 34) and an illumination of $150 \mu \mathrm{mol}$ photons $\mathrm{m}^{-2} \mathrm{~s}^{-1}$ supplied by cool white fluorescent lights in a 12:12 light:dark cycle. Seawater and nutrients were filter-sterilized $(0.22 \mu \mathrm{m})$. Cultures were maintained in 1000-mL flasks for 9-18 days before cells were harvested for the experiment.

\section{Noctiluca scintillans}

Cells from the March 2007 bloom in La Paz Bay in the Gulf of California were collected by vertical plankton net hauls $\left(60-\mu \mathrm{m}\right.$ mesh) at one station $\left(24^{\circ} 12.90^{\prime} \mathrm{N}\right.$, $110^{\circ} 19.57^{\prime} \mathrm{W}$; fig. 1). Plankton were transferred to a $150-\mathrm{L}$ ice chest and immediately brought to the laboratory in darkness. Dinoflagellate cells were slowly stirred and 5- to 20-mL samples were counted under a light microscope $(20 \times)$. An aliquot, containing $\sim 400 \mathrm{~N}$. scintillans cells, was gently poured into $1000-\mathrm{mL}$ flasks with $750 \mathrm{~mL}$ of G. catenatum culture.

Three concentrations of $G$. catenatum were tested (312, 625 , and 1015 cells $\left.\mathrm{mL}^{-1}\right)$ with $N$. scintillans ( $\sim 0.53$ cells $\left.\mathrm{mL}^{-1}\right)$. Each treatment was performed in triplicate. Gymnodinium catenatum (without $N$. scintillans) was mixed with seawater filtered through a $0.22-\mu \mathrm{M} \mathrm{GF} / \mathrm{F}$ filter that was collected at the same location as $N$. scintillans and added to a flask in the same proportion as the flasks used to calculate growth rates. As a control, an aliquot of $N$. scintillans was poured into filtered seawater without food. Conditions were área del florecimiento de $N$. scintillans y áreas colindantes. La temperatura superficial del agua de mar se determinó con un termómetro de cubeta, y los análisis de nutrientes (nitrato, fosfato y amonio) se realizaron con un autoanalizador de iones de flujo contínuo (QuikChem 8000 Series, Lachat Instruments, Milwaukee, WI) y mediante métodos espectrométricos descritos por Strickland y Parsons (1972) .

\section{Aislamiento y cultivo de Gymnodinium catenatum}

Se recolectaron células vegetativas de $G$. catenatum en bahía Concepción en el golfo de California mediante arrastres verticales con red de fitoplancton de $20 \mu \mathrm{m}$ de luz de malla. El concentrado celular se tamizó a través de una malla de $60 \mu \mathrm{m}$ para eliminar organismos de mayor tamaño. Este concentrado se colocó en recipientes de cultivo de tejidos de $250 \mathrm{~mL}$ que contenían agua de mar enriquecida con medio $\mathrm{f} / 2$ modificado adicionando $\mathrm{H}_{2} \mathrm{SeO}_{3}\left(0.01 \mu \mathrm{M} \mathrm{L} \mathrm{L}^{-1}\right)$ y la concentración de $\mathrm{CuSO}_{4}$ reducida a $0.01 \mu \mathrm{M} \mathrm{L}^{-1}$ (Anderson et al. 1984). En el laboratorio, las células vegetativas de $G$. catenatum se aislaron de los cultivos enriquecidos mediante micropipetas bajo un microscopio invertido (Axio Vert 100, Carl Zeiss, Oberkochen, Alemania). Las células individuales y cadenas se transfirieron a placas de 96 pozos que contenían medio $\mathrm{f} / 2$ modificado y se mantuvieron a $20 \pm 1{ }^{\circ} \mathrm{C}$ con una iluminación de $150 \mu \mathrm{mol}$ fotones $\mathrm{m}^{-2} \mathrm{~s}^{-1}$ con lámparas fluorescentes en un ciclo de luz:oscuridad 12:12. Para los experimentos, se utilizó la cepa GCCV-7 de G. catenatum. Los detalles de la cepa aislada se pueden consultar en los archivos de la Colección de Dinoflagelados Marinos (CODIMAR) del CIBNOR, La Paz, México (Morquecho 2008). Para obtener suficiente biomasa para los experimentos de pastoreo, la cepa GCCV-7 se cultivó en siete matraces de $1 \mathrm{~L}$ en medio $\mathrm{f} / 2$ modificado (Band-Schmidt et al. 2005) a $24-26^{\circ} \mathrm{C} \pm 1{ }^{\circ} \mathrm{C}$ con agua de mar obtenida de la bahía de La Paz (34 de salinidad) y con una iluminación de $150 \mu \mathrm{mol}$ fotones $\mathrm{m}^{-2} \mathrm{~s}^{-1}$ proporcionada con lámparas fluorecescentes en un ciclo luz:oscuridad 12:12. El agua de mar y los nutrientes se esterilizaron por filtración $(0.22 \mu \mathrm{m})$. Los cultivos se mantuvieron en matraces de $1000 \mathrm{~mL}$ de 9 a 18 días antes de cosechar las células para el experimento.

\section{Noctiluca scintillans}

Las células de $N$. scintillans del florecimiento presentado en Marzo de 2007 en la bahía de La Paz en el golfo de California se recolectaron mediante arrastres verticales de plancton (60 $\mu \mathrm{m}$ luz de malla) en una estación $\left(24^{\circ} 12.90^{\prime} \mathrm{N}\right.$, $110^{\circ} 19.57^{\prime}$ O; fig. 1). Las muestras de plancton se transportaron inmediatamente al laboratorio en una hielera de $150 \mathrm{~L}$ en oscuridad. Las células de dinoflagelados se agitaron suavemente, y se tomaron muestras de $5 \mathrm{~mL}$ y $20 \mathrm{~mL}$ para realizar conteos bajo un microscopio óptico $(20 \times)$. Suavemente se vacío una alícuota de $\sim 400$ células de $N$. scintillans en matraces de $1000 \mathrm{~mL}$ con $750 \mathrm{~mL}$ de cultivo de G. catenatum. 


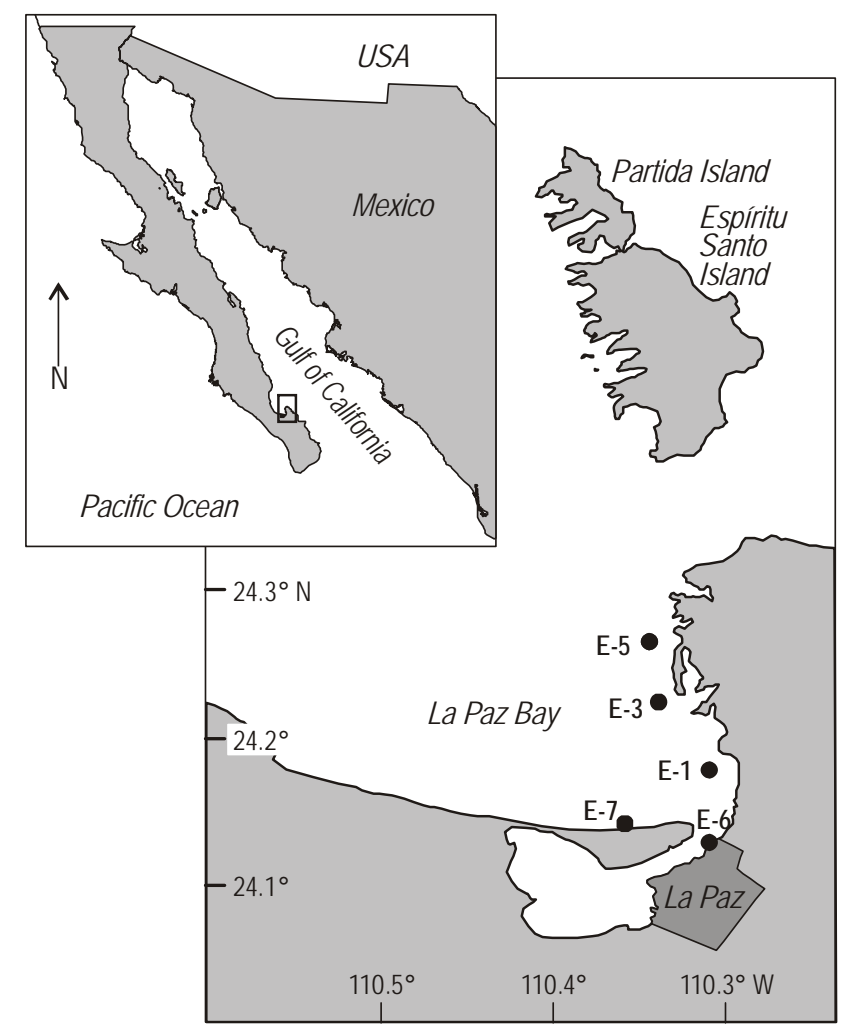

Figure 1. Map of the Gulf of California (left) indicating the sampling stations in La Paz Bay (right) for physical and chemical analyses. Noctiluca scintillans cells for the laboratory experiments and observations were collected at station E1.

Figura 1. Mapa del golfo de California (izquierda) que indica las estaciones de muestreo en la bahía de La Paz (derecha) donde se midieron los parámetros físicos y químicos. La recolecta de Noctiluca scintillans para los experimentos y las observaciones se hizo en la estación E1.

the same as those used for the maintenance of G. catenatum cultures. Once the experiment was set up, 2-mL samples of G. catenatum culture were used for counting at $0,24,48,72$, and $120 \mathrm{~h}$. One $100-\mathrm{mL}$ sample was fixed with lugol to calculate the proportion of $N$. scintillans with and without G. catenatum in their vacuoles. These concentrations were based on cell densities of previous $N$. scintillans (Uhlig and Sahling 1990, Kirchner et al. 1996, Cortés-Altamirano et al. 2007) and G. catenatum blooms (Band-Schmidt et al. 2010, Hallegraeff et al. 2012, Quijano-Scheggia et al. 2012).

\section{Ingestion rates}

Ingestion rates (IR) were estimated according to Frost (1972), where IR (number of G. catenatum/N. scintillans ${ }^{-1}$ $\left.\mathrm{h}^{-1}\right)=$ filtration rate $\left(\mathrm{mL}\right.$ cleared by each Noctiluca $\left.\mathrm{h}^{-1}\right) \times$ cell concentration (G. catenatum $\mathrm{mL}^{-1}$ ). Changes in growth (GR) or mortality (-GR) of $N$. scintillans were determined according to Bamstedt et al. (2000), where GR or $-\mathrm{GR}=$ $\left[\ln \left(N_{t+1}\right) / \ln \left(N_{t}\right)\right] / t$. Here, $N_{t}$ and $N_{t+1}$ are cell concentrations
Se probaron tres concentraciones de G. catenatum (312, 625 y 1015 células $\left.\mathrm{mL}^{-1}\right)$ con $N$. scintillans $(\sim 0.53$ células $\mathrm{mL}^{-1}$ ). Cada tratamiento se realizó por triplicado. Se mezcló G. catenatum ( $\sin N$. scintillans) con agua de mar filtrada a través de un filtro de $0.22 \mu \mathrm{M} \mathrm{GF} / \mathrm{F}$ que se recolectó en la misma localidad que se recolectó a $N$. scintillans y se colocó en un matraz en la misma proporción que los matraces utilizados para calcular las tasas de crecimiento. Una alícuota de $N$. scintillans fue colocada en agua de mar sin alimento y se utilizó como control. Las condiciones fueron las mismas que se emplearon para el mantenimiento de los cultivos de G. catenatum. Una vez montado el experimento, se tomaron muestras de $2 \mathrm{~mL}$ del cultivo de G. catenatum a las $0,24,48$, 72 y $120 \mathrm{~h}$ para su conteo. Se fijó una muestra de $100 \mathrm{~mL}$ con lugol para calcular la proporción de $N$. scintillans con y sin G. catenatum dentro de sus vacuolas. Estás concentraciones se basaron en las abundancias previas registradas en florecimientos de N. scintillans (Uhlig y Sahling 1990, Kirchner et al. 1996, Cortés-Altamirano et al. 2007) y G. catenatum (Band-Schmidt et al. 2010, Hallegraeff et al. 2012, QuijanoScheggia et al. 2012).

\section{Tasas de ingesta}

Las tasas de ingesta (TI) se estimaron de acuerdo con Frost (1972): TI (número de G. catenatum/N. scintillans ${ }^{-1}$ $\left.\mathrm{h}^{-1}\right)=$ tasa de filtración $(\mathrm{mL}$ eliminados por cada Noctiluca $\left.\mathrm{h}^{-1}\right) \times$ concentración celular (G. catenatum $\mathrm{mL}^{-1}$ ). Los cambios de $N$. scintillans por crecimiento (CR) o mortalidad (-CR) se determinaron de acuerdo con Bamstedt et al. (2000): CR o $-\mathrm{CR}=\left[\ln \left(N_{t+1}\right) / \ln \left(N_{t}\right)\right] / t$, donde $N_{t}$ y $N_{t+1}$ son las concentraciones celulares al tiempo $t$ y $t+1$, respectivamente. Este valor se dividió por $\ln (2)$ para expresar los resultados de divisiones por día.

\section{Observaciones de Noctiluca scintillans}

Se observaron las células vivas del campo y del laboratorio bajo un microscopio invertido. Se realizaron observaciones de $N$. scintillans y G. catenatum en cada tratamiento por triplicado a las 0, 24, 48, 72 y 120 h después de la incubación. Se tomaron fotografías de células vivas utilizando el software de análisis de imágenes (Image-Pro Plus, Media Cybernetics, Bethesda, MD) y una cámara digital acoplada a un microscopio (Olympus BX41, Olympus America, Central Valley, PA).

\section{Análisis estadísticos}

Se realizó un análisis de varianza (ANOVA) para determinar diferencias significativas en el crecimiento exponencial y las tasas de ingesta. Para determinar el efecto de cada tratamiento a cada intervalo de tiempo en cada variable respuesta, se llevó a cabo un ANOVA de una sola vía. Para determinar la normalidad de los datos, se aplicó una prueba de Kolmogorov-Smirnov. Si los datos no se ajustaban a la 
at time $t$ and $t+1$, respectively. This was divided by $\ln (2)$ to express the results as division per day.

\section{Observations of Noctiluca scintillans}

Live cells from field and laboratory samples were observed under a stereoscopic microscope. Observations of $N$. scintillans and $G$. catenatum cells were done for each treatment in triplicate at $0,24,48,72$, and $120 \mathrm{~h}$ after incubation. Photographs of live cells were taken using image analysis software (Image-Pro Plus, Media Cybernetics, Bethesda, MD) and a digital camera attached to a microscope (Olympus BX41, Olympus America, Central Valley, PA).

\section{Statistical analysis}

Differences in exponential growth and ingestion rates among treatments were tested by analysis of variance (ANOVA). To determine the effect of each treatment at each time interval on each response variable, one-way ANOVA was applied. Normality of fit was performed using the Kolmogorov-Smirnov test. If this assumption was not met, the data were log-transformed to fulfill the assumption. All analyses were performed using Statistica 5.0 (StatSoft, Tulsa, $\mathrm{OK})$ at a minimum significance level of $\alpha=0.05$.

\section{RESULTS AND DISCUSSION}

\section{Hydrological conditions in La Paz Bay during the Noctiluca scintillans bloom}

Sea surface temperature in La Paz Bay during the bloom (March 2007) was between 20 and $21.9^{\circ} \mathrm{C}$. Nutrient concentrations were relatively low $\left(<3 \mu \mathrm{mol} \mathrm{L}^{-1}\right)$ except for silicates (table 1). Historical silicate values in the area have been high (Lechuga-Devéze et al. 1986, Cervantes-Duarte et al. 2001, Reyes-Salinas et al. 2003) and linked to external land inputs (rain and silica-rich particles), as well as wind transport (Cervantes-Duarte et al. 2001). Vertical temperature profiles clearly showed the transition period from mixed to stratified distribución, éstos se transformaban a logaritmo. Todos los análisis se llevaron a cabo utilizando el programa Statistica 5.0 (StatSoft, Tulsa, OK) con un nivel mínimo de significancia de $\alpha=0.05$.

\section{RESULTADOS Y DISCUSIÓN}

\section{Condiciones hidrológicas en la bahía de La Paz durante el florecimiento de Noctiluca scintillans}

La temperatura superficial en la bahía de La Paz (Marzo, 2007) fue de entre 20 y $21.9^{\circ} \mathrm{C}$. Las concentraciones de nutrientes fueron relativamente bajas $\left(<3 \mu \mathrm{mol} \mathrm{L} \mathrm{L}^{-1}\right)$ excepto las del silicato (tabla 1). Los valores de silicatos en el área han sido altos (Lechuga-Devéze et al. 1986, CervantesDuarte et al. 2001, Reyes-Salinas et al. 2003) y se deben a los aportes terrestres externos (lluvia y partículas ricas en sílice), así como al transporte eólico (Cervantes-Duarte et al. 2001). Los perfiles verticales de temperatura mostraron de manera clara el periodo transicional de condiciones de mezcla a condiciones de estratificación en la bahía (Hernández-Sandoval et al. 2009). Estas condiciones se han asociado con la proliferación de $N$. scintillans en el sur del golfo de California, incluyendo la bahía de La Paz (Gárate-Lizárraga 1991, Cortés-Altamirano y Alonso-Rodríguez 1997) y también de G. catenatum (Cortés-Altamirano y Núñez-Pasten 1992, Cortés-Altamirano y Alonso-Rodríguez 1997, CortésAltamirano et al. 1999, Alonso-Rodríguez et al. 2005). En este caso, la proliferación de $N$. scintillans probablemente fue debida a las corrientes de advección o del viento desde las áreas adyacentes donde las condiciones físicas y químicas fueron adecuadas para su crecimiento. En el presente estudio, las condiciones hidrológicas fueron similares a las encontradas en otros eventos cuando G. catenatum estuvo presente en la bahía de La Paz (Hernández-Sandoval et al. 2009) y la bahía de Mazatlán (Cortés-Altamirano et al. 1999). Las aguas relativamente frías y ricas en nutrientes y la proliferación de G. catenatum en la bahía de Mazatlán han sido producto de eventos de surgencias (Cortés-Altamirano et al. 1999, Alonso-Rodríguez 2004) en el golfo de California.

Table 1. Physical and chemical data from samples collected in surface waters at stations in La Paz Bay during a Gymnodinium catenatum bloom.

Tabla 1. Parámetros físicos y químicos obtenidos de las aguas superficiales en las estaciones de la bahía de La Paz durante el florecimiento de Gymnodinium catenatum.

\begin{tabular}{cccccccc}
\hline Station & $\begin{array}{c}\text { Temperature } \\
\left({ }^{\circ} \mathrm{C}\right)\end{array}$ & $\begin{array}{c}\text { Dissolved oxygen } \\
\left(\mathrm{mL} \mathrm{L}^{-1}\right)\end{array}$ & $\begin{array}{c}\mathrm{NO}_{2} \\
(\mu \mathrm{M})\end{array}$ & $\begin{array}{c}\mathrm{NO}_{3} \\
(\mu \mathrm{M})\end{array}$ & $\begin{array}{c}\mathrm{NH}_{4} \\
(\mu \mathrm{M})\end{array}$ & $\begin{array}{r}\mathrm{PO}_{4} \\
(\mu \mathrm{M})\end{array}$ & $\begin{array}{c}\mathrm{SiO}_{2} \\
(\mu \mathrm{M})\end{array}$ \\
\hline E1 & 20.50 & 6.37 & 0.27 & 1.50 & 0.50 & 0.72 & 10.40 \\
E3 & 20.00 & 7.02 & 0.23 & 1.10 & 0.50 & 0.82 & 8.45 \\
E5 & 20.90 & 7.01 & 0.17 & 0.61 & 0.50 & 0.73 & 7.86 \\
E6 & 21.20 & 7.04 & 0.25 & 1.12 & 2.47 & 0.89 & 10.60 \\
E7 & 21.90 & 7.10 & 0.16 & 0.86 & 0.50 & 0.86 & 6.96 \\
\hline
\end{tabular}


conditions in the bay (Hernández-Sandoval et al. 2009). These conditions have been associated with a proliferation of $N$. scintillans in the southern Gulf of California, including La Paz Bay (Gárate-Lizárraga 1991, Cortés-Altamirano and Alonso-Rodríguez 1997), and G. catenatum (CortésAltamirano and Núñez-Pasten 1992, Cortés-Altamirano and Alonso-Rodríguez 1997, Cortés-Altamirano et al. 1999, Alonso-Rodríguez et al. 2005). In this case, the presence of a $N$. scintillans bloom was probably related to advection currents or wind transport from adjacent areas where suitable conditions for growth can be found. In our study, hydrological conditions were similar to previous events when $G$. catenatum was present in La Paz Bay (Hernández-Sandoval et al. 2009) and Mazatlán Bay (Cortés-Altamirano et al. 1999). The relatively cold and nutrient-rich water and the proliferation of G. catenatum in Mazatlán Bay were linked to upwelling events (Cortés-Altamirano et al. 1999, AlonsoRodríguez 2004) in the Gulf of California.

\section{Interaction of Noctiluca scintillans and Gymnodinium catenatum}

Our field observations show that $N$. scintillans engulfs $G$. catenatum (fig. 2). Numerous vacuoles contained single cells or chains of G. catenatum cells in mature (fig. 2a) and small trophonts (fig. 2b). Up to $40 \mathrm{G}$. catenatum cells were found in some Noctiluca cells (data not shown). Under natural conditions, $22 \%$ of $N$. scintillans cells were found with at least one or more G. catenatum cells in their vacuoles (fig. 3), suggesting that the $N$. scintillans population was still feeding. This percentage increased under experimental conditions to $70 \%$ and $94 \%$ (fig. 3). No statistical differences in the percentage of $N$. scintillans with engulfed dinoflagellates were observed among the three concentrations of G. catenatum, suggesting that the grazer was not satiated.

The natural diet of $N$. scintillans consists of an array of prey, including phytoplankton, nauplii, zooplankton eggs, organic detritus, and bacteria (Schaumann et al. 1988, Kirchner et al. 1996, Elbrächter and Qi 1998, Quevedo et al. 1999). Negative aspects of Noctiluca grazing on Acartia clausi eggs and nauplii have been reported. Along the Cantabrian coast of Spain, $N$. scintillans ingested $73 \%$ of the total stock of $A$. clausi eggs, suggesting a negative effect on the absolute recruitment of nauplii (Quevedo et al. 1999). Our results of predation by $N$. scintillans confirm observations by Alonso-Rodríguez et al. (2005) and Albinsson et al. (2006); the large number of $N$. scintillans with engulfed G. catenatum under experimental conditions confirms high acceptance of $G$. catenatum as prey. Ingestion rates ranged from 0 to 19.4 cells h$^{-1}$ (fig. 4). This consumption was variable within the same diet level (as shown by the standard deviation), and it did not show a clear pattern related to prey concentration and incubation time. However, in treatments with 625 and 1015 cell $\mathrm{mL}^{-1}$, a decreasing rate after $48 \mathrm{~h}$ is evident. Hansen et al. (2004) state that the green form of $N$.

\section{Interaccion de Noctiluca scintillans y Gymnodinium catenatum}

Las observaciones de campo muestran claramente que $N$. scintillans ingiere G. catenatum (fig. 2). Se registraron numerosas vacuolas que contenían células de G. catenatum individuales o en cadenas tanto en trofontes maduros (fig. 2a) como en organismos pequeños (fig. 2b). En algunos casos se observaron hasta 40 células de G. catenatum dentro de $N$. scintillans (datos no mostrados). En las muestras de campo, $22 \%$ de $N$. scintillans se encontraron con al menos una célula de G. catenatum en sus vacuolas (fig. 3), lo que sugiere que la población de $N$. scintillans aún estaba alimentándose. El porcentaje se incrementó a $70 \%$ y $94 \%$ en las muestras de los experimentos realizados (fig. 3). El análisis estadístico no mostro diferencias significativas en los porcentajes de $N$. scintillans con la presa en su interior entre las tres concentraciones de G. catenatum probadas, lo que sugiere que no existió una saciedad del alimento.

La dieta natural de $N$. scintillans incluye varias presas, como fitoplancton, nauplios, huevos de zooplancton, detritus orgánico y bacterias (Schaumann et al. 1988, Kirchner et al. 1996, Elbrächter y Qi 1998, Quevedo et al. 1999). Se han documentado algunos aspectos negativos del pastoreo de Noctiluca sobre huevos de Acartia clausi y nauplios. En las costas Cantabrianas (España), N. scintillans ingirió 73\% de la totalidad de los huevos de Acartia clausi, lo que llevó a sugerir un efecto negativo en el reclutamiento de los nauplios a la población (Quevedo et al. 1999). Nuestros resultados confirman los resultados de Alonso-Rodríguez et al. (2005) y Albinsson et al. (2006) sobre la ingesta que $N$. scintillans realiza sobre G. catenatum, además de que el alto porcentaje de $N$. scintillans con G. catenatum en el interior de sus vacuolas sugiere que esta presa es de alta aceptación. Las tasas de ingesta variaron de 0 a 19.4 células $\mathrm{h}^{-1}$ (fig. 4). Estas tasas fueron variables dentro del mismo tratamiento (como lo demuestra la desviación estándar), y no se observó un patrón de consumo claro relacionado con las diversas dietas ni con el tiempo de experimentación. Sin embargo, en el tratamiento con densidad intermedia y alta de la presa es evidente que la tasa de consumo disminuyó luego de las $48 \mathrm{~h}$. Hansen et al. (2004) encontraron que la forma verde de $N$. scintillans alimentado con Pyrodinium bahamense var. compressum tuvo una tasa de ingesta de de $\sim 16$ células de $P$. bahamense $\mathrm{d}^{-1}$ a una densidad de 540 células $\mathrm{mL}^{-1}$. Estos autores observaron que las tasas de ingesta incrementaron linealmente con el incremento de la concentración de la presa, aunque tampoco observaron saciedad. Nakamura (1998) registraron que cuando $N$. scintillans fue alimentada con dos especies de rafidofitas, Chattonella antiqua y Heterosigma akashiwo, las tasas de ingesta aumentaron linealmente con la concentración de la presa, y estas tasas alcanzaron 4.1 células de C. antiqua $\mathrm{h}^{-1}$ y 62.5 células de $H$. akashiwo $\mathrm{h}^{-1}$ a la máxima concentración de la presa de $\sim 500$ células de $C$. antiqua $\mathrm{mL}^{-1}$ y $\sim 11,000$ células de $H$. akashiwo $\mathrm{mL}^{-1}$. En este último 

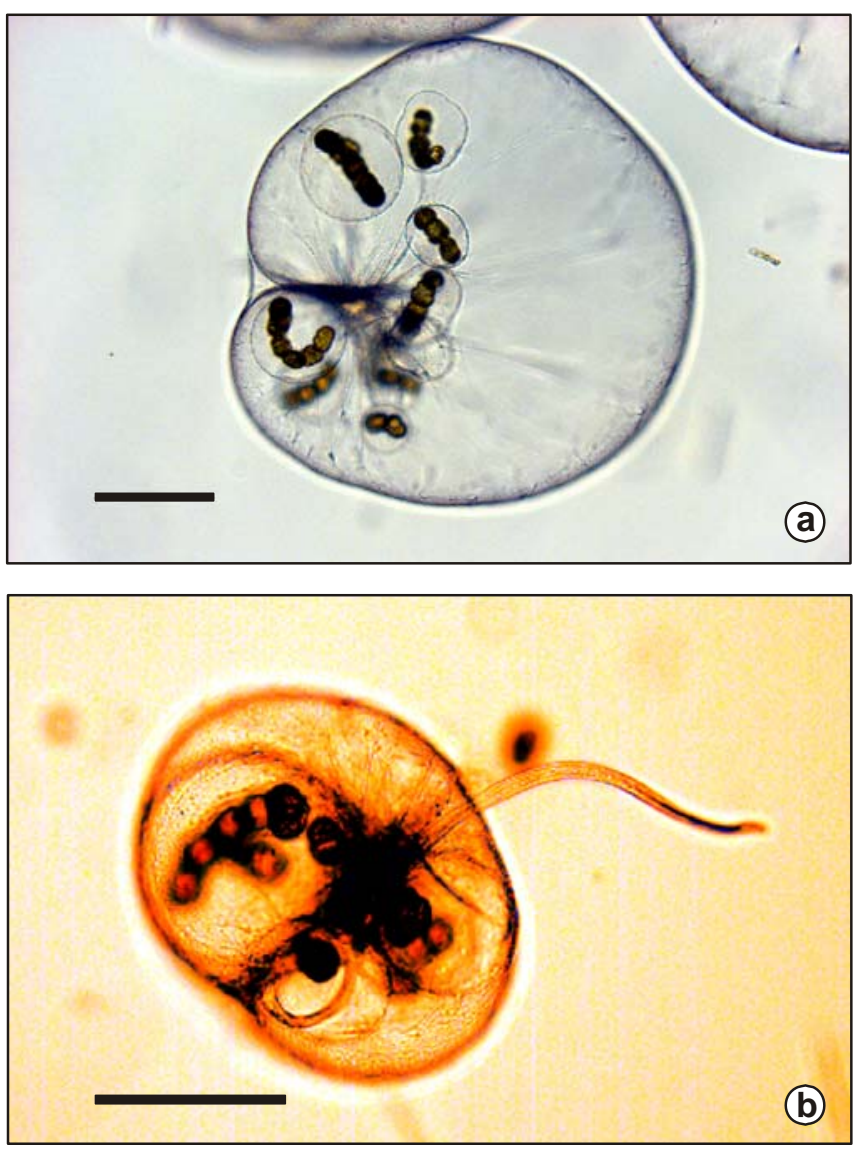

Figure 2. Noctiluca scintillans with engulfed dinoflagellate Gymnodinium catenatum in digestive vacuoles. (a) Vegetative mature trophont with up to 34 G. catenatum cells. (b) Small trophont. Bar $=100 \mu \mathrm{m}$.

Figura 2. Fotografías de Noctiluca scintillans con el dinoflagelado Gymnodinium catenatum dentro de sus vacuolas digestivas. (a) Trofonte maduro con hasta 34 células de $G$. catenatum en su interior. (b) Trofonte pequeño. Barra $=100 \mu \mathrm{m}$.

scintillans feeds on Pyrodinium bahamense var. compressum at an ingestion rate of $\sim 16 P$. bahamense cells $\mathrm{d}^{-1}$ at a high prey density of 540 cells $\mathrm{mL}^{-1}$. They also noted that ingestion rates increased linearly with increasing prey concentration, with no indication of satiation. Nakamura (1998) found that when $N$. scintillans was fed two raphidophyte species, Chattonella antiqua and Heterosigma akashiwo, grazing rates increased linearly with the concentration of the prey, reaching 4.1 C. antigua cells $\mathrm{h}^{-1}$ and $62.5 \mathrm{H}$. akashiwo cells $\mathrm{h}^{-1}$ at a maximum prey level of $\sim 500$ C. antigua cells $\mathrm{mL}^{-1}$ and $\sim 11,000 \quad H$. akashiwo cells $\mathrm{mL}^{-1}$. In Nakamura's study, smaller spherical cells (diameter $<5 \mu \mathrm{m}$ ) of species such as Isochrysis galbana and Chlamydomonas parkeae were unsuitable prey. Clearly, cell size is important in the grazing rate of $N$. scintillans with higher rates on bigger diameter cells. The size of the G. catenatum cells used in our study ranged from 20 to $30 \mu \mathrm{m}$. Our results show relatively high ingestion rates; however, to our knowledge, there

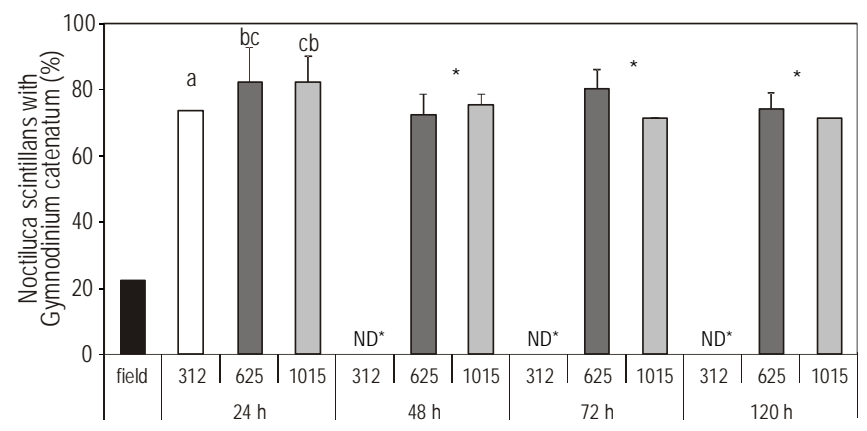

Figure 3. Incidence of Noctiluca scintillans with engulfed Gymnodinium catenatum when fed varying concentrations of G. catenatum $\left(312,625\right.$, or 1015 cells $\left.\mathrm{mL}^{-1}\right)$ during 1-, 2-, 3-, and 5 -day incubation periods $(\mathrm{ND}=$ not determined). Experiments were performed in 1-L glass flasks filled with $750 \mathrm{~mL}$ seawater in triplicate. The asterisk indicates no statistical differences. Columns with the same letter do not differ significantly at a minimum significance level of $\alpha=0.05$ (e.g., for $24 \mathrm{~h}$, the incidence [\%] in treatment $\mathrm{a}$ is different from $\mathrm{b}$ and $\mathrm{c}$ but the incidence [\%] in treatment $b$ is not different from c). Bars represent the standard deviation.

Figura 3. Porcentaje de incidencia de Noctiluca scintillans con células de Gymnodinium catenatum en sus vacuolas en las diferentes dietas experimentales de G. catenatum $(312,625$ y 1015 células $\mathrm{mL}^{-1}$ ) en los diferentes periodos de incubación $(1,2$, 3 y 5 días) ( $\mathrm{ND}=$ no determinado). Los experimentos se realizaron por triplicado en matraces de $1 \mathrm{~L}$ de capacidad con $750 \mathrm{~mL}$ de agua de mar. El asterisco indica que no hubo diferencias significativas. Las columnas con las mismas letras no son diferentes significativamente $(\alpha=0.05$; e.g., para las $24 \mathrm{~h}$, la incidencia [\%] del tratamiento a es diferente de b y c pero la incidencia [\%] en el tratamiento b no es diferente de c). Las barras perpendiculares representan la desviación estándar.

estudio, las especies con un diámetro esférico menor (diámetro $<5 \mu \mathrm{m}$ ), tal como Isochrysis galbana y Chlamydomonas parkeae, no fueron adecuadas como presa. Esto demuestra la importancia del tamaño de la presa ya que $N$. scintillans ingiere en mayor cantidad presas de mayor tamaño. El diámetro de las células de G. catenatum utilizadas en nuestros experimentos oscilaron entre 20 y $30 \mu \mathrm{m}$. Las tasas de ingesta en el presente estudio fueron relativamente altas; sin embargo, hasta donde sabemos, no existen trabajos sobre la ingesta de $N$. scintillans sobre G. catenatum, por lo que la comparación realizada anteriormente debe tomarse con precaución. De acuerdo con Yilmaz et al. (2005), N. scintillans tiene una estrategia de alimentación oportunista tipo $r$. Esta estrategia es evidente en este trabajo, sugerida por las altas tasas de consumo mostradas. Bajo condiciones naturales, se han observado hasta 18 huevos de A. clausi (Quevedo et al. 1999) o 27 huevos de copépodos (Daan 1987) en una sola célula de $N$. scintillans. Nuestros resultados sugieren también que este dinoflagelado tiene una capacidad alta de pastoreo. Otras características, aparte del tamaño, como la toxicidad o el perfil de toxinas del dinoflagelado pueden 
are no quantitative studies of $G$. catenatum ingestion by $N$. scintillans. Direct comparisons with other studies, including those mentioned here, are only suggestive. Noctiluca scintillans is a successful $r$-strategist, with its opportunistic feeding behavior (Yilmaz et al. 2005); its high predation capacity is evident from its high ingestion rates. Under natural conditions, up to 18 A. clausi eggs (Quevedo et al. 1999) or 27 copepod eggs have been observed in a single $N$. scintillans cell (Daan 1987). Our results also support high predation capacity. Additionally, another prey characteristic, toxicity or toxin profiles among dinoflagellates can affect variations in the grazing rate. The strain used in this study is less toxic than other Mexican strains (average 13 pg STXeq cell ${ }^{-1}$ ), with a dominance of C-type sulfocarbamoils (Band-Schmidt et al. 2010). The sulfocarbamoil group contains one of the least potent toxins of PSP analogues (Oshima 1995).

Growth of $N$. scintillans was important in all treatments, almost doubling the initial inoculum during day 1 ( 0.43 to $0.70 \mathrm{~d}^{-1}$ ), and steadily decreasing until day 3 of incubation, when null or negative growth occurred (fig. 5). On day 5, positive growth was observed in the low and high concentrations of G. catenatum ( 0.37 and $0.14 \mathrm{~d}^{-1}$, respectively). A significant difference was only found on day 1 between treatments with 625 and 1015 cell $\mathrm{mL}^{-1}$. Incubated only with seawater and culture medium (two controls), N. scintillans also had positive growth $\left(0.40 \mathrm{~d}^{-1}\right)$ on day 1 , but these cells died after the second day of incubation (data not shown). These results suggest that $N$. scintillans cells could grow because of its photosynthetic capacity or the food previously ingested under natural conditions (G. catenatum and other planktonic cells). However, absence of growth on day 3 of incubation suggests that G. catenatum is of low nutritional value or that it produces metabolites that negatively affected the growth of $N$. scintillans after prolonged feeding on this species. Death may also occur from the build-up of toxic metabolites from $N$. scintillans itself, since they were present at high densities. Azanza et al. (2009) observed that feeding $P$. bahamense to $N$. scintillans and then introducing an alternative prey or organic nutrient slowed the grazing impact of $N$. scintillans on P. bahamense, and that growth of $N$. scintillans was greater when it was incubated with an additional mixed prey.

Interestingly, many deformed $N$. scintillans cells were observed at the end of the experiment. These cells had their crust around them and resembled zygotes from the earliest development stage (fig. 6a, b). Some of these zygotes had vacuoles containing G. catenatum cells (fig. 6b). According to Fukuda (Tohoku University, Japan; pers. comm.), mature trophonts shed their crust and become small spherical cells when they are damaged and react this way to renovate themselves. It is plausible that, in spite of grazing activity by $N$. scintillans, G. catenatum is not a good food for this predator under the experimental conditions we used for several days. Frangópulos et al. (2000) reported that fecundity and egg production of $A$. clausi were negatively affected when fed the

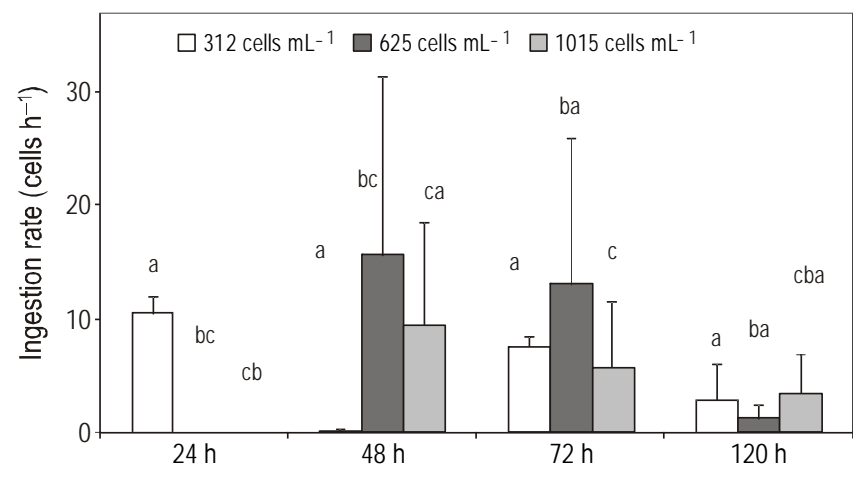

Figure 4. Average ingestion rates of Noctiluca scintillans fed one of three concentrations of Gymnodinium catenatum $(312,625$, or 1015 cells $\mathrm{mL}^{-1}$ ) during 1-, 2-, 3-, and 5-day incubation periods. Experiments were performed in 1-L glass flasks filled with $750 \mathrm{~mL}$ seawater and performed in triplicate. Columns with the same letter do not differ significantly at a minimum significance level of $\alpha=0.05$. (e.g., for $24 \mathrm{~h}$, the ingestion rate in treatment a is different from $\mathrm{b}$ and $\mathrm{c}$ but the ingestion rate in treatment $\mathrm{b}$ is not different from c). Bars represent the standard deviation.

Figura 4. Tasa de ingesta promedio de Noctiluca scintillans alimentada con las diversas dietas experimentales de Gymnodinium catenatum $\left(312,625\right.$ y 1015 células $\mathrm{mL}^{-1}$ ) en los diferentes periodos de incubación (1, 2, 3 y 5 días). Los experimentos se realizaron por triplicado en matraces de $1 \mathrm{~L}$ de capacidad con $750 \mathrm{~mL}$ de agua de mar. Las columnas con las mismas letras no son diferentes significativamente $(\alpha=0.05$; e.g., para las $24 \mathrm{~h}$, la tasa de ingesta del tratamiento a es diferente de $b$ y c pero la tasa de ingesta en el tratamiento $b$ no es diferente de c). Las barras perpendiculares representan la desviación estándar.

tener un efecto en las tasas de pastoreo. La cepa utilizada en este trabajo es de las menos tóxicas de otras cepas aisladas de las costas mexicanas (promedio 13 pg STXeq célula ${ }^{-1}$ ), con un perfil dominado por las toxinas sulfocarbamoil tipo $\mathrm{C}$ (Band-Schmidt et al. 2010). Este grupo de toxinas son las menos potentes de los análogos de la saxitoxina (Oshima 1995).

El crecimiento de $N$. scintillans fue importante en todas las dietas, casi duplicándose en el primer día (de 0.43 a $\left.0.70 \mathrm{~d}^{-1}\right)$ y luego disminuyendo ligeramente hasta el tercer día de incubación, cuando se observó un crecimiento nulo o negativo (fig. 5). En el día 5, se observó un crecimiento positivo en los tratamientos de menor y mayor concentración de G. catenatum ( 0.37 y $0.14 \mathrm{~d}^{-1}$, respectivamente). Sin embargo solo se encontraron diferencias significativas para el día 1 entre los tratamientos con 625 y 1015 células $\mathrm{mL}^{-1}$. Noctiluca scintillans, incubada sólo en agua de mar y medio de cultivo (dos controles), también tuvo un crecimiento positivo hasta el día $1\left(0.40 \mathrm{~d}^{-1}\right)$, pero las células murieron luego de ese tiempo (datos no mostrados). Estos resultados sugieren que $N$. scintillans pudo crecer debido a su capacidad fotosintética o debido al alimento que había ingerido previo a su captura 


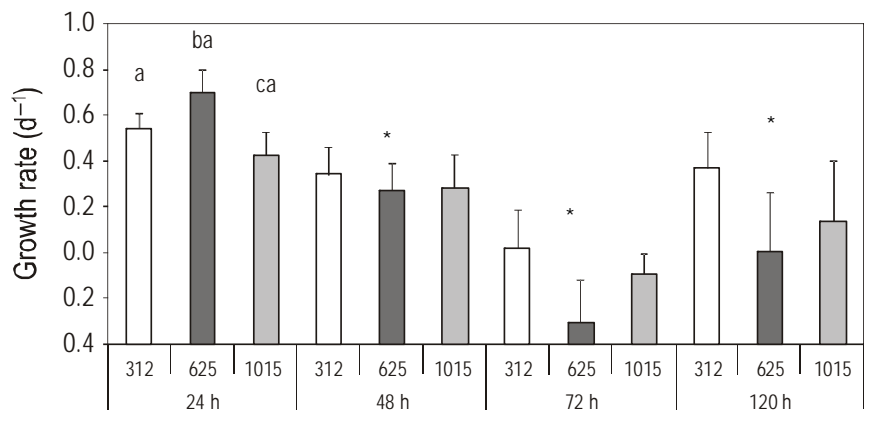

Figure 5. Daily growth rates of Noctiluca scintillans fed one of three concentrations of Gymnodinium catenatum $(312,625$, or 1015 cells $\mathrm{mL}^{-1}$ ) during 1-, 2-, 3-, and 5-day incubation periods. Experiments were performed in 1-L glass flasks filled with $750 \mathrm{~mL}$ seawater and performed in triplicate. The asterisk indicates no statistical differences. Columns with the same letter do not differ significantly at a minimum significance level of $\alpha=0.05$ (e.g., for $24 \mathrm{~h}$, the growth rate in treatment a is the same as in $b$ and $c$ but the growth rate in treatment $b$ is different from $c$ ). Bars represent the standard deviation.

Figura 5. Tasa de crecimiento diaria de Noctiluca scintillans alimentada con las diversas dietas experimentales de Gymnodinium catenatum (312, 625 y 1015 células $\mathrm{mL}^{-1}$ ) en los diferentes periodos de incubación (1, 2, 3 y 5 días). Los experimentos se realizaron por triplicado en matraces de $1 \mathrm{~L}$ de capacidad con $750 \mathrm{~mL}$ de agua de mar. El asterisco indica que no hubo diferencias significativas. Las columnas con las mismas letras no son diferentes significativamente $(\alpha=0.05$; e.g., para las $24 \mathrm{~h}$, la tasa de crecimiento del tratamiento a es igual que b y c pero la tasa de crecimiento del tratamiento $b$ es diferente de c). Las barras perpendiculares representan la desviación estándar.

PSP-producing Alexandrium minimum over several days and suggest that there was a threshold limit for toxins assimilated by this copepod. This means that when copepods feed on toxic cells, some of the assimilated energy is used to eliminate or manage toxins and less energy is channeled into egg production (Dutz 1998). This is consistent with our observations of $N$. scintillans shedding its cytoplasmic membrane after ingesting toxic cells for several days.

\section{CONCLUSIONS}

Noctiluca scintillans exerts high predation pressure on the PSP-producing dinoflagellate G. catenatum, under natural and laboratory conditions, but this dinoflagellate does not seem to be able to sustain the growth of $N$. scintillans for more than five days because it causes biochemical damage to $N$. scintillans. These results support the proposal of using this mixotrophic dinoflagellate as a biocontrol agent during the proliferation of G. catenatum; however, the small differences in the ingestion rates of the different prey densities offered indicates that $N$. scintillans has limited biocontrol capacity. If the finding of excretion/bioconversion by Azanza et al. (2009) is applicable, then predation by $N$. scintillans may be
(G. catenatum y otras presas). Aunque si consideramos que luego del tercer día hubo un crecimiento nulo o negativo, entonces podemos suponer que G. catenatum puede ser una presa con un contenido nutricional bajo o bien que produce metabolitos que afectan el crecimiento de $N$. scintillans luego de alimentarse con G. catenatum por un tiempo relativamente largo. La muerte también pude asociarse a los metabolitos tóxicos del mismo $N$. scintillans por la alta densidad utilizada. Azanza et al. (2009) observaron que al alimentar a $N$. scintillans con $P$. bahamense y luego con una presa alternativa o sustancias orgánicas, la depredación sobre el dinoflagelado disminuyó y el crecimiento de $N$. scintillans fue mayor cuando tenía las presas adicionales.

Al final de los experimentos se encontraron muchas células de $N$. scintillans deformadas. Estas células se parecían a los cigotos de los estadios iniciales de desarrollo pero con una cubierta externa flácida a su alrededor (fig. 6a, b). Algunos de estos cigotos tenían vacuolas con células de $G$. catenatum (fig. 6b). Según Fukuda (Tohoku University, Japón; com. pers.), los trofontes maduros dejan su cubierta externa y se transforman en células esféricas, tipo cigoto, cuando hay un daño a la célula para luego renovarse. De lo anterior, es factible pensar que a pesar de que $N$. scintillans se alimenta de G. catenatum, este dinoflagelado no fue un alimento adecuado durante las incubaciones. Frangópulos et al. (2000) ha documentado que tanto la fecundidad como la producción de huevos por A. clausi fueron afectados cuando los adultos fueron alimentados con el dinoflagelado productor de toxinas paralizantes Alexandrium minimum por varios días. Estos autores también sugieren que el copépodo al alimentarse llega a un umbral que se autolimita por la asimilación de las toxinas. Esto se interpreta como la utilización de parte de la energía asimilada para eliminar o manejar las toxinas, por lo que menos energía se canaliza hacia la producción de huevos (Dutz 1998). Esto es consistente con nuestra observación de cigotos de $N$. scintillans que se desprendieron de la membrana celular luego de la ingestión de células tóxicas por varios días.

\section{CONCLUSIONES}

Noctiluca scintillans ejerce una depredación importante sobre el dinoflagelado G. catenatum, tanto en condiciones naturales como en condiciones de laboratorio; sin embargo, esta presa parece no ser adecuada para sostener el crecimiento de $N$. scintillans por más de cinco días, probablemente debido al daño bioquímico ejercido por G. catenatum. La utilización de $N$. scintillans como biocontrol de florecimientos de G. catenatum se apoya con estos resultados; sin embargo, el hecho de que no hubo diferencias en las tasa de ingesta en las diversas densidades de G. catenatum ofrecidas indica que $N$. scintillans tiene una capacidad de biocontrol limitada. Si la capacidad de excreción/biotransformación de toxinas paralizantes de $N$. scintillans registrada por Azanza et al. (2009) se aplica a este modelo, entonces el consumo de 
effective for the control of toxins produced by G. catenatum. Production of ammonium by Noctiluca (Montani et al. 1998) and its role in stimulating the growth of $G$. catenatum must be investigated because G. catenatum has a high affinity for ammonium (Yamamoto et al. 2004). The fate of toxins, as well as the optimal ratio of Noctiluca and G. catenatum density, merits further research to understand its potential to control the saxitoxin-producing G. catenatum and its role in bloom dynamics when both species are present.

\section{ACKNOWLEDGMENTS}

Funding for this study was provided by institutional projects SIP 2013-0942 (CICIMAR), PC3.1 and PC3.2 (CIBNOR), and CONACYT projects (SEP2007-84064, SNI2008-90102, 178227). We thank J Bashan for kindly providing the use of the microscope and camera, and Ira Fogel of CIBNOR for editing services. We also thank the anonymous reviewers for their important suggestions that improved the manuscript.

\section{REFERENCES}

Albinsson ME, Blackburn SI, Legrand C. 2006. The effect of Noctiluca scintillans on harmful algal species of southeastern Australia. Abstract of ISSHA 12th International Conference on Harmful Algae (Copenhagen, Denmark), p. 123.

Alonso-Rodríguez R. 2004. Hidrología y condiciones ambientales que determinan la proliferación de dinoflagelados causantes de mareas rojas en la bahía de Mazatlán, Sin., México. PhD thesis, Centro de Investigaciones Biológicas del Noroeste, La Paz, BCS, México, $117 \mathrm{pp}$.

Alonso-Rodríguez R, Ochoa JL, Uribe-Alcocer M. 2005. Grazing of heterotrophic dinoflagellate Noctiluca scintillans (Mcartney) Kofoid on Gymnodinium catenatum Graham. Rev. Latinoam. Microbiol. 47: 6-10.

Anderson DM, Kulis DM, Binder BJ. 1984. Sexuality and cyst formation in the dinoflagellate Gonyaulax tamarensis: Cyst yield in batch cultures. J. Phycol. 20: 418-425. http://dx.doi.org/10.1111/j.0022-3646.1984.00418.x

Azanza RV, Cruz LJ, Cariño FA, Blanco AG, Butardo Jr VM. 2009. Paralytic shellfish toxin concentration and cell density changes in Pyrodinium bahamense - Noctiluca scintillans feeding experiments. Toxicon 55: 1017-1023.

http://dx.doi.org/10.1016/j.toxicon.2009.09.017

Bamstedt U, Gifford DJ, Irigoin X, Atkinson A, Roman M. 2000. Feeding. In: Harris R, Wiebe P, Lenz J, Skjoldal HR, Huntley M (eds.), ICES Zooplankton Methodology Manual. Academic Press, London, pp. 297-399.

Band-Schmidt CJ, Bustillos-Guzmán J, Gárate-Lizárraga I, Lechuga-Devéze CH, Reinhard K, Luckas B. 2005. Paralytic shellfish toxin profile in strains of the dinoflagellate Gymnodinium catenatum Graham and the scallop Argopecten ventricosus G.B. Sowerby II from Bahía Concepción, Gulf of California, Mexico. Harmful Algae 4: 21-31. http://dx.doi.org/10.1016/j.hal.2003.10.004

Band-Schmidt CJ, Bustillos-Guzmán JJ, López-Cortés DJ, GárateLizárraga I, Núñez-Vázquez EJ, Hernández-Sandoval FE. 2010. Ecological and physiological studies of Gymnodinium catenatum in the Mexican Pacific: A review. Mar. Drugs 8: 1935-1961.

http://dx.doi.org/10.3390/md8061935
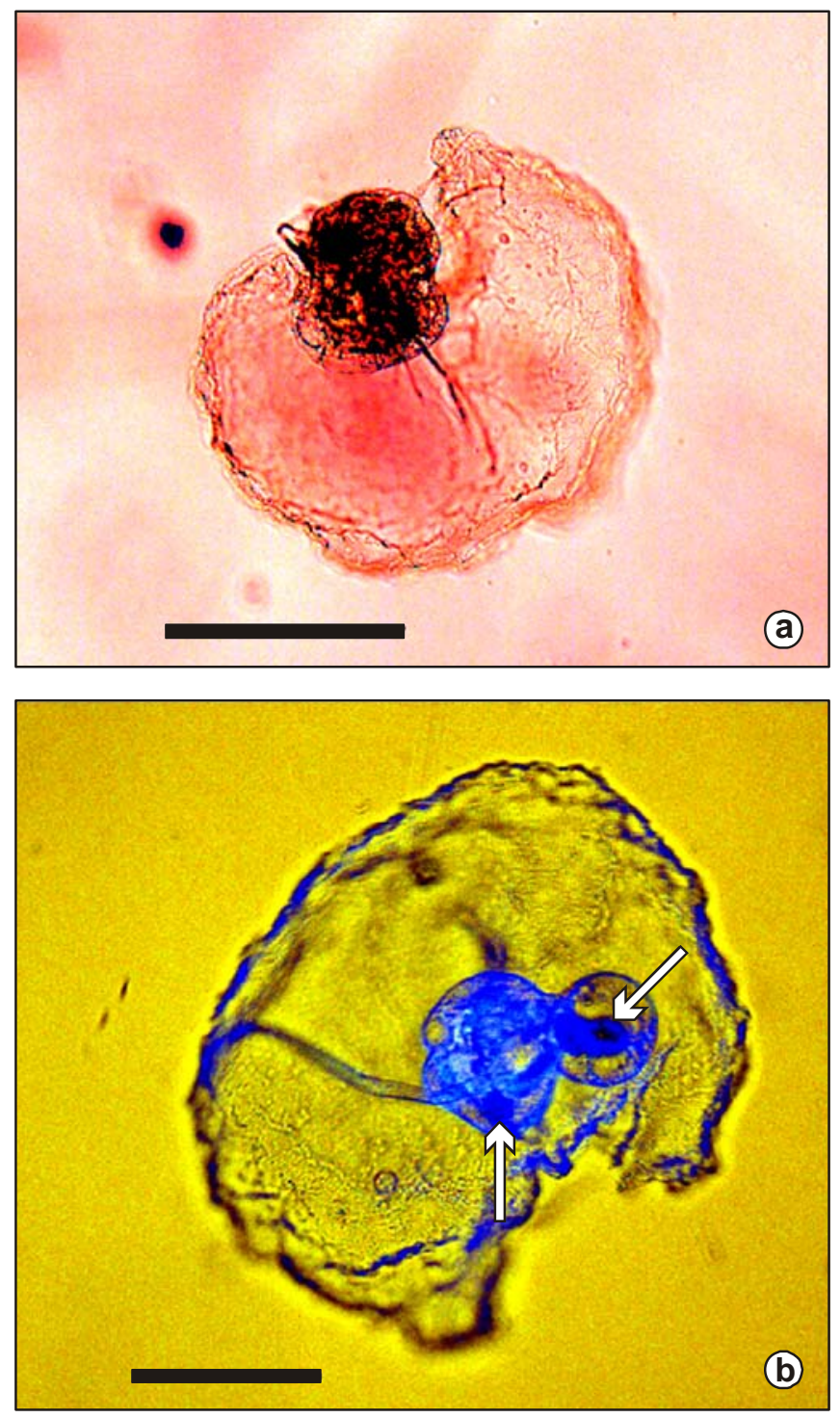

Figure 6. Noctiluca scintillans cells shedding their cytoplasmic membrane at the end of the trial. (b) Gymnodinium catenatum cells (arrows) are visible within the vacuoles. The diameter of the crust is $\sim 300 \mu \mathrm{m}$. Bar $=100 \mu \mathrm{m}$.

Figura 6. Células de Noctiluca scintillans desprendiéndose de su membrana externa al final del experimento. (b) Algunas células de Gymnodinium catenatum (flechas) se ven claramente dentro de las vacuolas de $N$. scintillans. El diámetro de la membrana es de $\sim 300 \mu \mathrm{m}$. Barra $=100 \mu \mathrm{m}$.

$N$. scintillans podría ser adecuado para controlar las toxinas producidas por $G$. catenatum. También se debe considerar que $N$. scintillans es un productor de amonio (Montani et al. 1998), que posiblemente sea un estimulador del crecimiento de G. catenatum. Este es un tema que debe investigarse, ya que se ha demostrado que $G$. catenatum tiene una alta afinidad hacia el amonio (Yamamoto et al. 2004). Se debe investigar lo que sucede con las toxinas, así como el número adecuado de células de Noctiluca que pueden utilizarse para controlar a la población G. catenatum, antes de su utilización 
Cervantes-Duarte R, Aguirre-Bahena F, Reyes-Salinas A, ValdezHolguín JE. 2001. Caracterización hidrológica de una laguna costera de Baja California Sur, México. Oceánides 16: 93-105.

Cortés-Altamirano R, Núñez-Pastén A. 1992. Doce años (1979-1990) de registros de mareas rojas en la Bahía de Mazatlán, Sin., México. An. Inst. Cienc. Mar Limnol. Univ. Nac. Auton. Mex. 19: 113-121.

Cortés-Altamirano R, Hernández-Becerril DU, Luna-Soria R. 1995. Mareas rojas en México: Una revisión. Rev. Latinoam. Microbiol. 37: 343-52.

Cortés-Altamirano R, Alonso-Rodríguez R. 1997. Mareas rojas durante 1997 en la Bahía de Mazatlán, Sinaloa, México. Ciencias del Mar 15: 31-37.

Cortés-Altamirano R, Núñez-Pasten A, Pasten-Miranda N. 1999. Abundancia anual de Gymnodinium catenatum Graham dinoflagelado tóxico de la costa este del Golfo de California. Ciencia y Mar 7: 50-56.

Cortés-Altamirano R, Serrano-Hernández DE, Sierra-Beltrán AP. 2007. A bloom of Noctiluca scintillans and its possible cysts in the Gulf of California, Mexico. Harmful Algae News 34: 6-7.

Daan R. 1987. Impact of egg predation by Noctiluca miliaris on the summer development of copepod populations in the southern North Sea. Mar. Ecol. Prog. Ser. 37: 9-17.

Dutz J. 1998. Repression of fecundity in neritic copepod Acartia clausi exposed to the toxic dinoflagellate Alexandrium lusitanicum: Relationship between feeding and egg production. Mar. Ecol. Prog. Ser. 175: 97-107. http://dx.doi.org/10.3354/meps 175097

Elbrächter M, Qi Y-Z. 1998. Aspects of Noctiluca (Dinophyceae) population dynamics. In: Anderson DM, Cembella AD, Hallegraeff GM (eds), Physiological Ecology of Harmful Algal Blooms. NATO ASI Ser. G 41. Springer-Verlag, Berlin, pp. 315-335.

Escalera L, Pazos Y, Moroño Á, Reguera B. 2007. Noctiluca scintillans may act as a vector of toxigenic microalgae. Harmful Algae 6: 317-32. http://dx.doi.org/10.1016/j.hal.2006.04.006

Fonda-Umani S, Beran A, Parlato S, Virgilio D, Zollet T, DeOlazabal A, Lazzarini B, Cabrini M. 2004. Noctiluca scintillans (Mccartney) in the Northern Adriatic Sea: Long-term dynamics, relationship with temperature and eutrophication, and role in the food web. J. Plankton Res. 26: 545-561. http://dx.doi.org/10.1093/plankt/fbh045

Frangópulos MC, Guisande C, Maneiro I. Rivero I, Franco J. 2000. Short- and long-term effects of the toxic dinoflagellate Alexandrium minutum on the copepod Acartia clausi. Mar. Ecol. Prog. Ser. 203: 161-169.

http://dx.doi.org/10.3354/meps203161

Frangópulos M, Spyrakos E, Guisante C. 2011. Ingestion and clearance rates of the red Noctiluca scintillans fed on the toxic dinoflagellate Alexandrium minutum (Halim). Harmful Algae 10:304-309. http://dx.doi.org/10.1016/j.hal.2010.11.002

Frost BW. 1972. Effects of size and concentration of food particles on the feeding behavior of the marine planktonic copepod Calanus pacificus. Limnol. Oceanogr. 17: 805-815.

Fukuda Y, Endoh H. 2006. New details from the complete life cycle of the red-tide dinoflagellate Noctiluca scintillans (Ehrenberg) McCartney. Eur. J. Protistol. 42: 209-219.

Gárate-Lizárraga I. 1991. Análisis de una marea roja causada por Noctiluca scintillans (McCartney) Ehrenberg en Bahía Concepción, Baja California Sur, en febrero de 1989. Rev. Invest. Cient. 2: 35-43.

Hallegraeff GM, Blackburn SI, Doblin MA, Bolch CJS. 2012. Global toxicology, ecophysiology and population relationships como biocontrol de G. catenatum; también es necesario comprender la participación de $N$. scintillans en la dinámica del florecimiento.

\section{Agradecimientos}

Este estudio fue financiado con los proyectos institucionales SIP 2013-0942 (CICIMAR), PC3.1 y PC3.2 (CIBNOR), y proyectos CONACyT (SEP 2007-84064, SNI2008-90102, 178227). Agradecemos a J Bashan por prestarnos la camara y el microscopio y a Ira Fogel la edición del trabajo en inglés. También agradecemos a los revisores anónimos sus sugerencias, que ayudaron a mejorar este trabajo

of the chainforming PST dinoflagellate Gymnodinium catenatum. Harmful Algae 14: 130-143.

http://dx.doi.org/10.1016/j.hal.2011.10.018

Hansen JP, Miranda L, Azanza R. 2004. Green Noctiluca scintillans: A dinoflagellate with its own greenhouse. Mar. Ecol. Prog. Ser. 275: 79-87.

http://dx.doi.org/10.3354/meps 275079

Hernández-Sandoval FE, López-Cortés DJ, Núñez-Vázquez EJ, Band-Schmidt CJ, Gárate-Lizárraga I, Bustillos-Guzmán JJ, 2009. Comparative paralytic shellfish toxin profile in six bivalve molluscs during the first outbreak of Gymnodinium catenatum in Bahía de La Paz, Mexico. 2007. Hidrobiológica 19: 245-256.

Kirchner M, Sahling G, Uhlig G, Gunkel W, Klings KW. 1996. Does the red tide-forming dinoflagellate Noctiluca scintillans feed on bacteria? Sarsia 81: 45-55.

Lechuga-Devéze $\mathrm{CH}$, García-Pámanes J, Bustillos-Guzmán JJ. 1986. Condiciones ecológicas de una laguna costera de la costa oeste del Golfo de California. Turbiedad y clorofila $a$. Cienc. Mar. 12(1): 19-31.

Morquecho L. 2008. Colección de Dinoflagelados Marinos (CODIMAR). Centro de Investigaciones Biológicas del Noroeste, S.C. La Paz, BCS, México, http://www.cibnor.mx/es/ investigacion-joomla/colecciones-biologicas/codimar.

Montani S, Pithakpol S, Tad K. 1998. Nutrient regeneration in coastal seas by Noctiluca scintillans, a red tide-causing dinoflagellate. J. Mar. Biotechnol. 6: 224-228.

Nakamura Y. 1998. Growth and grazing of a large heterotrophic dinoflagellate, Noctiluca scintillans, in laboratory cultures. J. Plankton Res. 20: 1711-1720. http://dx.doi.org/10.1093/plankt/20.9.1711

Oshima Y. 1995. Post-column derivatization liquid chromatographic method for paralytic shellfish toxins. J. AOAC Int. 78: 528-532.

Quevedo M, González-Quiros R, Anadon R. 1999. Evidence of heavy predation by Noctiluca scintillans on Acartia clausi (Copepoda) eggs off the central Cantabrian coast (NW Spain). Oceanol. Acta 22: 127-131.

Quijano-Scheggia S, Olivos-Ortiz A, Bustillos-Guzmán JJ, Garcés E, Gaviño-Rodríguez J, Galicia-Pérez MC, Patiño-Barragán M, Band-Schmidt CJ, Hernández-Sandoval FJ, López-Cortés D. 2012. Bloom of Gymnodinium catenatum Graham in Bahía Santiago and Bahía Manzanillo, Colima, Mexico. Rev. Biol. Tropical 60: 173-186.

Reyes-Salinas A, Cervantes-Duarte R, Morales-Pérez RA, ValdezHolguín JE. 2003. Variabilidad estacional de la productividad primaria y su relación con la estratificación vertical en la Bahía de La Paz, BCS. Hidrobiológica 13: 103-110. 
Schaumann K, Gerdes D, Hesse KJ, 1988. Hydrographic and biological characteristics of a Noctiluca scintillans red tide in the German Bight, 1984. Meeresforschung 32: 77-91.

Strickland JDH, Parsons TR. 1972. A Practical Handbook of Seawater Analysis. 2nd ed. Bull. Fish. Res. Bd. Canada, Ottawa, $310 \mathrm{pp}$.

Uhlig G, Sahling G. 1990. Long-term studies on Noctiluca scintillans in the German Bight. Population dynamics and red tide phenomena 1968-1988. Neth. J. Sea Res. 25: 101-112.
Yamamoto T, Oh SJ, Kataoka Y. 2004. Growth and uptake kinetics for nitrate, ammonium and phosphate by the toxic dinoflagellate Gymnodinium catenatum isolated from Hiroshima Bay, Japan. Fish. Sci. 70: 108-115.

Yilmaz IN, Okus E, Yuksek A. 2005 Evidences for influence of a heterotrophic dinoflagellate (Noctiluca scintillans) on zooplankton community structure in a highly stratified basin. Estuar. Coast. Shelf Sci. 64: 475-485.

Received October 2012, received in revised form April 2013, accepted April 2013. 